\title{
Challenges of additive manufacturing technologies from an optimisation perspective
}

\author{
Sofiane Guessasma ${ }^{1, *}$, Weihong Zhang ${ }^{2}$, Jihong $\mathrm{Zhu}^{2}$, Sofiane Belhabib ${ }^{3}$, and Hedi Nouri ${ }^{4}$ \\ 1 INRA, UR1268 Biopolymères Interactions Assemblages, 44300 Nantes, France \\ 2 Laboratory of Engineering Simulation \& Aerospace Computing-ESAC, Northwestern Polytechnical University, 710072 Xian, Shaanxi, \\ P.R. China \\ 3 LUNAM University of Nantes Angers Le Mans, CNRS, GEPEA, UMR 6144, IUT de Nantes, 2 avenue du Professeur Jean Rouxel, \\ 44475 Carquefou Cedex, France \\ 4 Department of Polymers and Composites Technology \& Mechanical Engineering, Mines Douai, 941 rue Charles Bourseul, CS 10838, \\ 59508 Douai, France
}

Received 29 October 2015 / Accepted 31 December 2015

\begin{abstract}
Three-dimensional printing offers varied possibilities of design that can be bridged to optimisation tools. In this review paper, a critical opinion on optimal design is delivered to show limits, benefits and ways of improvement in additive manufacturing. This review emphasises on design constrains related to additive manufacturing and differences that may appear between virtual and real design. These differences are explored based on 3D imaging techniques that are intended to show defect related processing. Guidelines of safe use of the term "optimal design" are derived based on 3D structural information.
\end{abstract}

Key words: Additive Manufacturing, Topological optimisation, Process-induced defects, X-ray micro-tomography.

\section{Introduction}

Additive Manufacturing (AM) is a collection of versatile techniques of rapid prototyping that allow material design from 3D digital models [1-3]. The term AM comes also under different other nicknames such as direct digital manufacturing or solid freeform fabrication $[4,5]$. AM is rated as one of the most promising technology for design [6], presented as a new industrial revolution [7], and a vector for creativity [8], impact [9] and interrogations [10]. The laying down of the material in different states including liquid, powder and fused material defines roughly categories of AM [2, 7, 11-13]. More accurate classifications do exist such as the ASTM F42 reported in reference [14]. Wide varieties of materials can be processed using additive manufacturing including metals [15-18], alloys [19-22], ceramics [23-26], polymers [27-30], composites [31-34], airy structures $[35,36]$ and multi-phase materials [37-39].

The main characteristic of AM is the reduced number of manufacturing steps that stands between the virtual design and the ready-to-use part [40]. In addition, one major advantage of AM reported in the literature is the ability to process

*e-mail: sofiane.guessasma@nantes.inra.fr complex shapes that are not easy to design using traditional ways such as extrusion and moulding [3, 41, 42]. AM potential, as a leading design technique, is enormous and the related applications are huge [7, 43-47]. Different printing techniques are used in the biomedical sector $[41,48]$ more particularly for tissue engineering $[5,35,49-51]$. Preform design of composites is evidently an inspiring topic for AM [31] because of the wide possibilities in structuring yarns and reinforcing composite structures [34]. Aerospace applications of AM are the most challenging because of the extreme performance that need to be achieved under fine scale monitoring and in-service validation $[52,53]$. Recent contributions by NPU demonstrates the central role of topology optimisation in additive manufacturing for aerospace applications [54, 55]. Micro-fabrication technologies emerge also as an efficient way to produce functional micro-components for microelectronics systems [42]. The scaling down of AM is now possible thanks to cutting edge processes that allow material design at a very fine scale like with different types of lithography $[55,56]$.

The idea behind $\mathrm{AM}$ is the direct import of $\mathrm{CAD}$ (Computer-Aided-Design) object as machine instructions (Figure 1). The preferred way to achieve this import is the transformation of surface tessellation representing the geometry of the virtual part into a set of toolpaths. One starts from an 


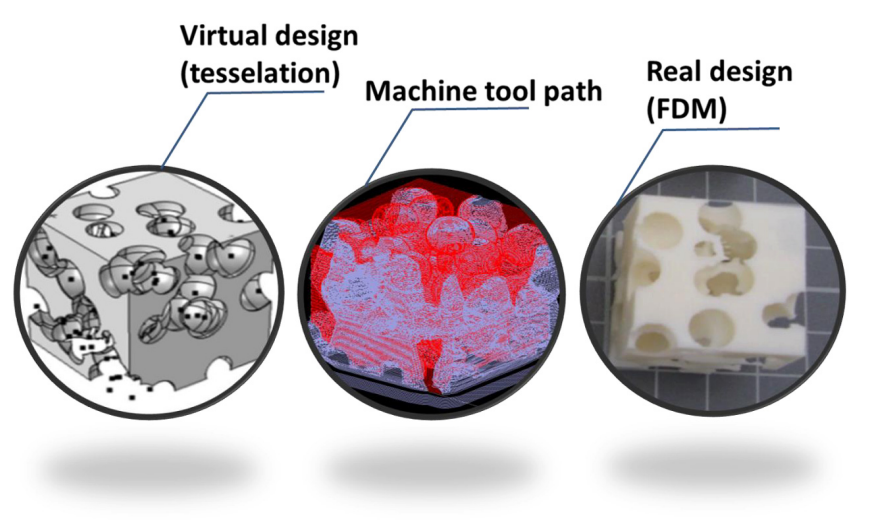

Figure 1. The process chain in typical AM.

STL or Standard Tessellation Language or STereoLithography file. All external boundaries and internal surfaces appear smooth and continuous using STL format. Generation of the toolpaths represents the first challenge and actually a limitation for AM [57]. The reason is that the building process in most 3D printing technologies relies on a successive layer-by-layer building process. So, starting from 3D space tessellation and ending with 2D building strategy is a first drawback. It is even worse when droplet based printing is considered because the fused matter is no more connected in any direction. Discontinuities may appear in all building directions (Figure 2) as a result of the layer-by-layer laying down process (Figure 3) [27]. The consequence of this appears to be the development of dimensional inaccuracy, inacceptable finishing state, structural and mechanical anisotropies, which are continuously addressed in many research contributions [12, 28, 58-64]. Anisotropy can be also inferred to the development of particular grain texture as revealed by laser melting deposition or arc welding alloying of metals [61, 65-68]. Reduction of anisotropy can be achieved by selecting the appropriate orientation of the virtual design [69-71]. Numerous papers mention strategies of common sense to build parts with acceptable performance, which are nearly equivalent or even superior to other design techniques. Scudino and others $[67,72]$ report that better ductility of metallic materials can be achieved using selective laser melting compared to casting as a result of the fine grain structure driven by AM. One particular feature highlighted in these contributions refers to avoid building the part along its largest surface. In other words, if the successive layers of the part exhibit a lack of cohesion, the large contact area between layers drives worse performance under tension. Some other strategies rely on reducing the lack of cohesion between layers or filaments by further processing of the real design. An example of radiation treatment is proposed in the work of Shaffer et al. [28].

In addition to the role of anisotropy, differences between the virtual and real design can be striking knowing that AM resolution is finite due to available tooling [64]. If we consider the example of fused deposition modelling, which is a popular AM technique [12], the toolpath generation is referred as collection of filament paths of finite dimensions (Figure 3). This has three main consequences on the real design: internal structural features may not be well captured depending on their size; discontinuities may appear depending on local curvature; and the surface finishing state may be limited due to rough profiles [62]. These limitations are illustrated in Figure 2, which highlights simple and complex geometries and the corresponding toolpath generation using two software, one is Repetier from Hot-World $\mathrm{GmbH} \& \mathrm{Co}$, Germany and the other is CatalystEx from Stratasys Inc. Eden Prairie MN, USA.

All limitations mentioned earlier assume implicitly the role of defects induced by AM. These need to be faced in order to deliver a design representing, with much accuracy, the result of an optimisation procedure. These defects are related to the porosities that develop as a consequence of the discontinuous process of printing and other issues related to process errors [73]. A large number of contributions is dedicated to the evaluation of the effect of porosities in printed parts. One particular consequence of the role of porosity is that a large amount of them reduces the mechanical performance. Such reduction is represented by a theoretical linear decrease of stiffness with the increase porosity level (if limited stress transfer between layers is neglected). Under tension, porosities act as stress concentrators and may induce lower mechanical strength by enhancing the development of damage in the form of micro-cracks. Under compression, different considerations can be pointed out. Even if the porosities are closed during compressive loading, lateral expansion due to Poisson's effect may cause failure driven by opening mode or shearing effects that are dramatically enhanced by the anisotropy [27, 58].

Porosity should not be considered systematically as a negative issue in $\mathrm{AM}$ since it can be a positive driving factor for permeability [74].

Another type of defects is the presence of support material trapped between internal surfaces. The material is needed to withstand the fragile printed structure during the printing process. While this material is studied to provide limited adhesion to the deposited materials, its residual amount contributes in increasing the weight of the structure and modifies the load bearing distributions. These two drawbacks alter the expected performance of the optimal design. In addition, none-optimised support deposition affects finishing state, material consumption, fabrication time, etc. [75]. Strategies exist to reduce the dependence of AM to the presence of a support material by operating smart or slimming support generation $[75,76]$. For some strategies, the part orientation is continuously adapted during the processing [57]. Curved regions can be processed smoothly under continuous deposition mode and the presence of support material is no more needed. For other strategies, building complex shape without the support material relies on the intrinsic properties of the deposited material itself. These materials exhibit generally rapid cooling kinetics, which allow them to support their own weight and prevent the structure collapsing. This kind of strategies obviously limits the spectrum of materials that can be printed.

\section{Optimisation in additive manufacturing}

In this paper, our focus goes towards optimisation difficulties that are inferred to AM. With regards to the large number 


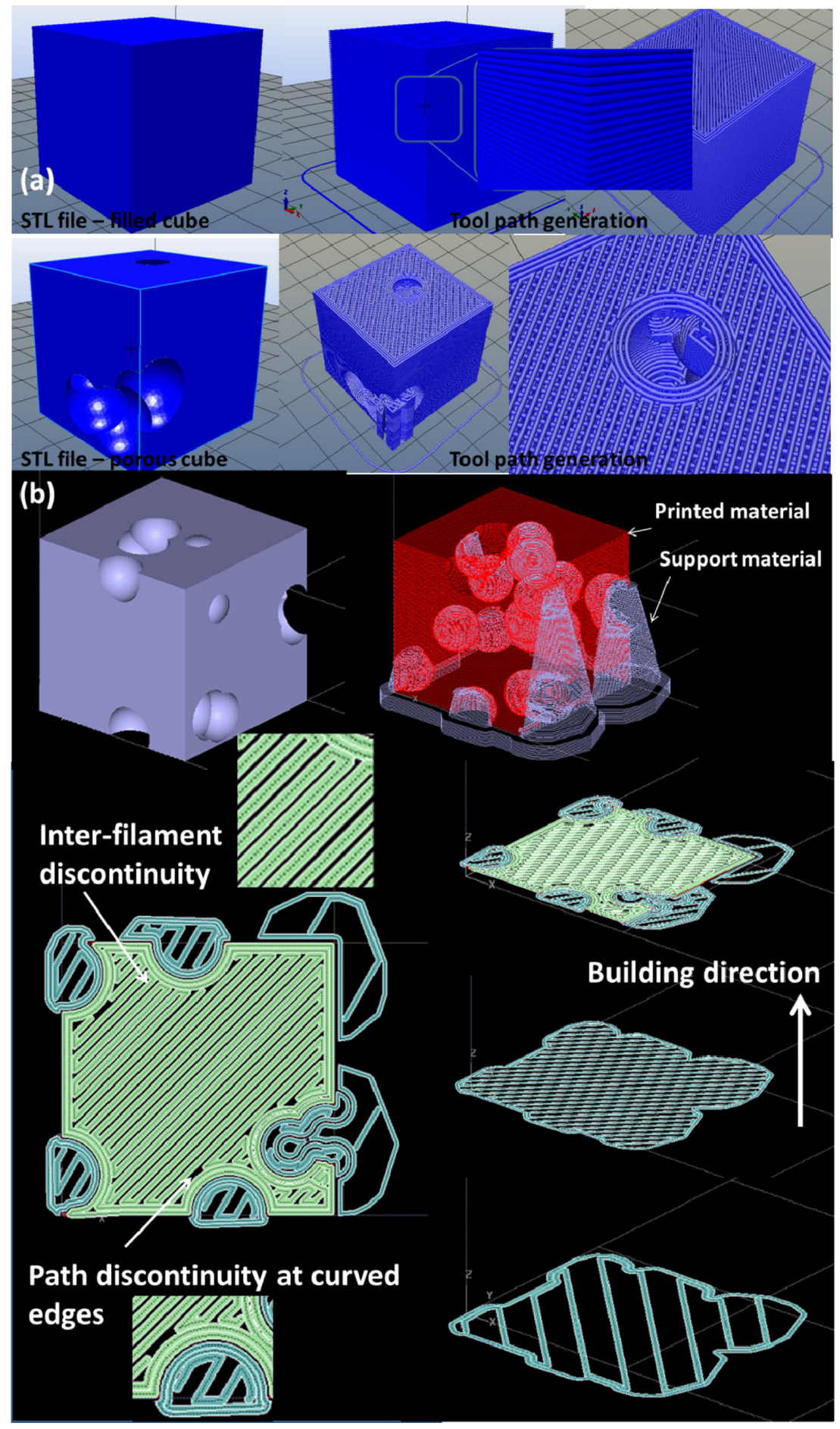

Figure 2. Typical examples of CAD objects transformed into collection of toolpaths using (a) Repetier and (b) CatalystEX software.

of disseminated works on the subject, common characteristics of optimisation in AM are highlighted in this section and described through selective literature work. In particular, several aspects of additive manufacturing can be optimized. Some of these aspects are related to design optimisation, more particularly topology optimisation. Some others like geometry accuracy, finishing state are tackled through process planning optimisation.
For most contributions, optimisation in AM is classically considered as a process parameter optimisation as it is the case for many design techniques [77, 78]. Raster angle, building direction, layer dimensions are some of the main parameters that find some interest in the literature. For instance, Garg et al. [79] present genetic programming approach as an intelligence tool to relate the AM process parameters to physical and structural outputs. While this is an important issue from the 

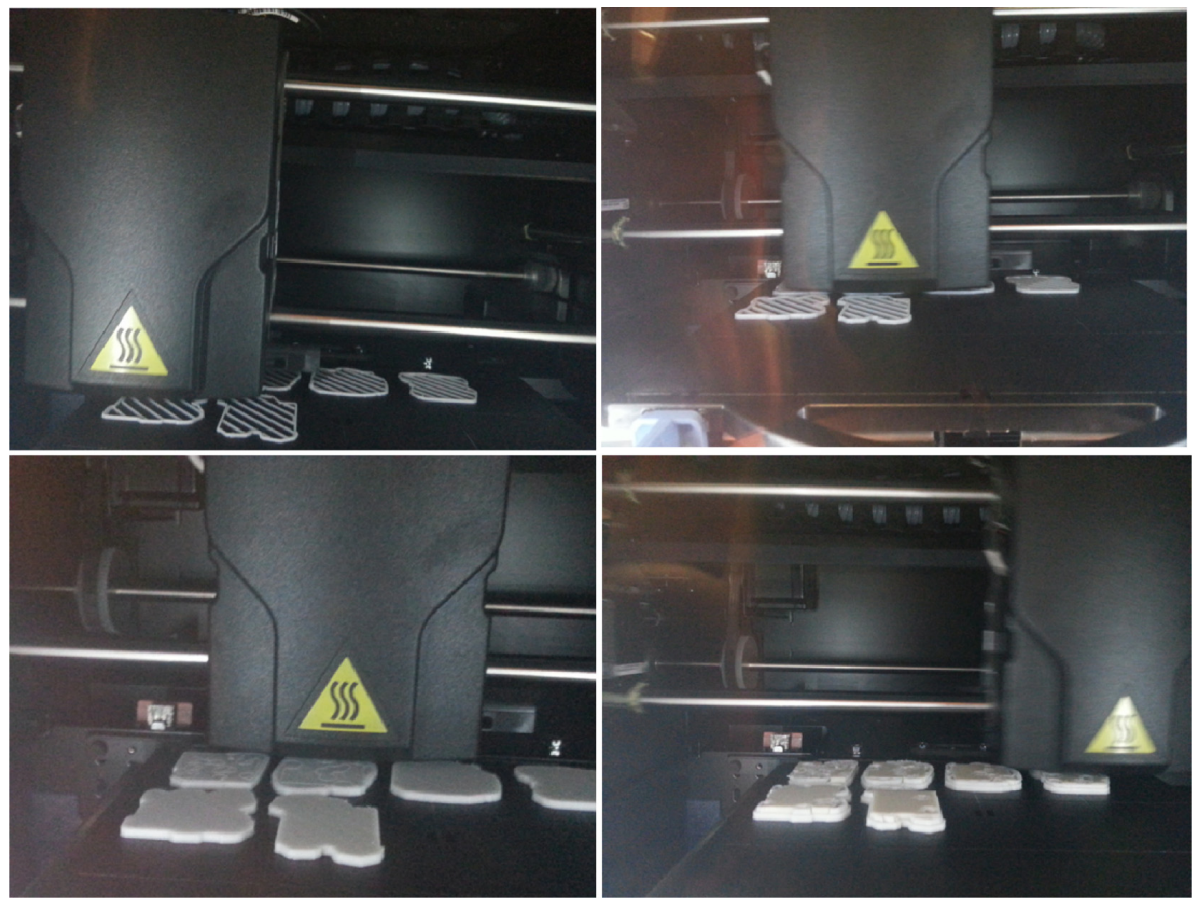

Figure 3. Laying down process of fused ABS polymer in typical FDM equipment.

processing viewpoint, it is less attractive from a numerical analysis perspective, where strong and robust optimisation tools need to address more significant challenges. This does not diminish the purpose of the earlier approach. Accurate dimension, acceptable roughness and processing time are some of the important outcomes that justify the continuity of the research effort in this particular field. A typical example showing the importance of the process optimisation is provided in recent works [54, 55, 78]. The paper by Zhou et al. [78] introduces the concept of pixel blending to define the effect of neighbour pixels light intensity in solid freeform fabrication using photopolymerisation medium. The optimisation in such kind of studies is meaningful as the achievement of shape accuracy relies on the precise control of light intensity over a pixel-based image.

The paper by Yang and Zhao [3] report one of the most recent review on AM-enabled design, which is the closest subject to topology optimisation. In their review, design guidelines are exposed and the focus on structure optimisation methodology is explored through different contributions. This kind of methodologies needs to take care about the specificities of the design in terms of material combination, shape complexity and the targeted in-service performance. In the same review [3], the authors bring to our attention the possibilities of process combination involving more conventional or AM-based techniques [80-82]. We consider that this research direction associating various processes is out of the scope of this paper from an angle view of topology optimisation. However, the other considerations discussed there are central to the topology optimisation such as those related to design simplicity, material choice efficiency, improved multi-functionality, integrated technical solutions [83], etc. The concepts of multiphase material [37] and functionally graded materials $[84,85]$ emerge as a direct consequence to point by point material control in AM [86]. Also, designers are no more bonded by the tooling which needs to be a factor in the design with traditional processing [87]. This opens new chances for simplifying the design but also for increasing the creativity [7]. This particular point helps significantly the designers who need generally to reshape the result of the topology procedure to fit processing constrains like the development of particular tooling. A simple example would be the conversion of a material deposition probability into a graded material [4] instead of thresholding to solid or air phase [88]. In addition, if the conditions of blending at the microscale or nanoscale are met, the achievement of multi-material design is not a threat for the design but mostly an advantage because of the possibility to further improve performance at a lower material consumption rate [4].

Considerations related to topology optimisation are numerous $[37,88]$. Some of them depend on the level of access to the AM processing technology itself which is not systematically provided by the commercial solutions. Here are some of these considerations that are central to the development of robust AM solutions:

- Geometry of the CAD model: this is direct target of the topology optimisation, which needs to predict what would be the exact geometry that satisfies all model constrains. Successful examples of topology optimisation can be found in the literature for cellular materials [88, 89], multiphase materials [37], implants [90].

- Path generation: this is an important parameter that affects geometry accuracy, cohesion in the part, residual stresses, and the finishing state [20, 63, 91]. Path generation needs to handle as much the change in process speed and the transition time at the borders [92]. A specific 
(a)

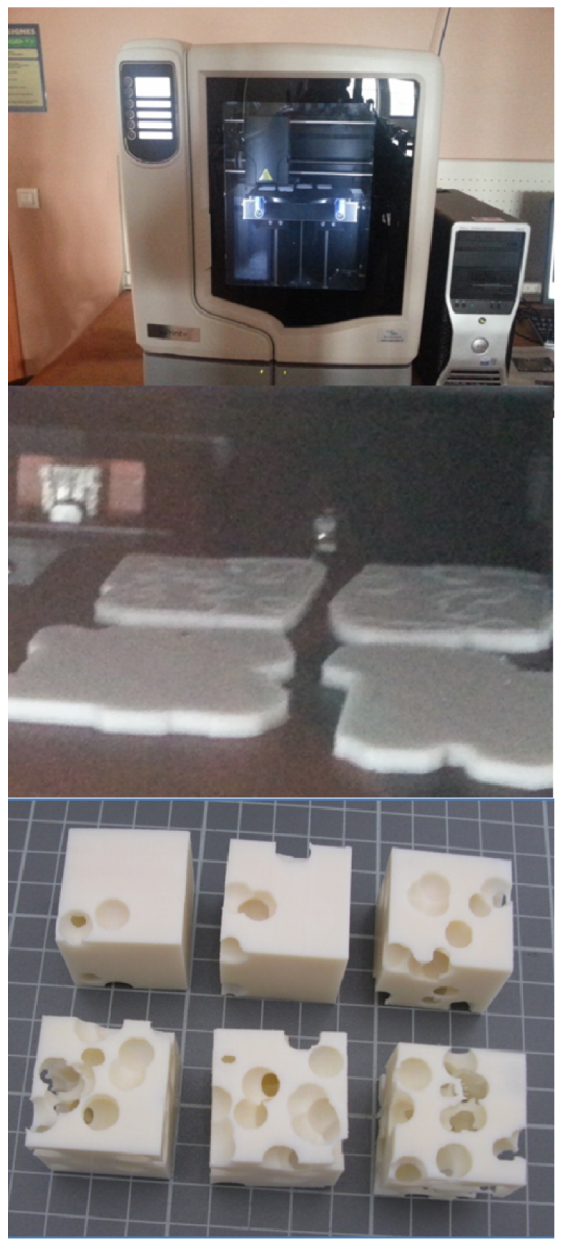

(b)

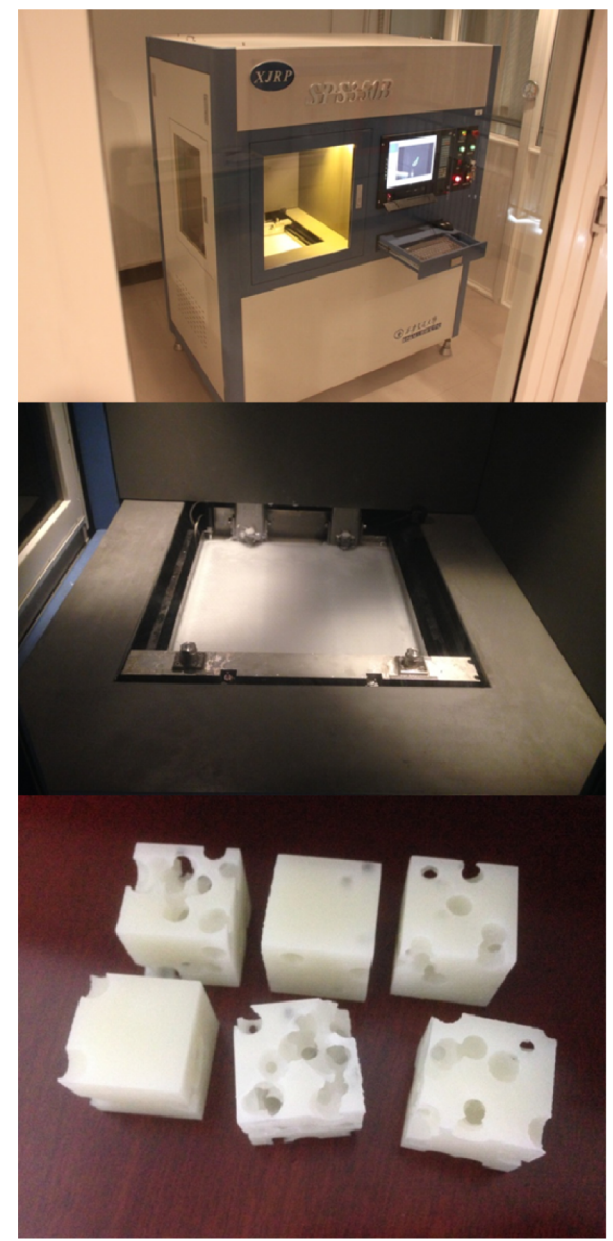

Figure 4. Two examples of airy randomly structured polymers designed using (a) fused disposition modelling (uPrint equipment in GEPEA lab., university of Nantes, France) and (b) photolithography (SPS350B equipment in ESAC lab, NPU, Xian, China).

branch of research is dedicated to the optimisation of tool generation path including studies related to the improvement of the scanning mode [93, 94], geometry slicing strategies [95, 96], optimal material deposition [97, 98], multi-directional AM [99], tool path anticipation procedures [100].

- Process selection: different technologies are developed to enhance the capabilities of AM like jet printing [26, 101], friction stir AM [102], welding based AM [94], ultrasonic AM [103], electrochemical AM [104], micro-plasma powder deposition [105], Solid freeform fabrication [106] and related variants such as selective laser sintering [107, 108], or directed light fabrication [20], selective infiltration manufacturing [109]). The outcomes of these technologies diverge. This reinforces specific aspects of AM like the material type, printing size, accuracy, speed, cost, etc. [110]. Figure 4 shows two examples of technologies applied for the design of airy structures, one based on FDM (uPrint ${ }^{\circledR}$ SE from Stratasys) and the other is a photolithography equipment (SPS350B from XJRP company). The earlier one is restricted to printing ABS polymer where the last one can process only photosensitive resins. The ability to control the process parameters is crucial to decide on the relevance of a particular AM process [111]. And perhaps, a badly performing design reflects only the lack of knowledge of the process. Thus, the mastering of the process parameters is a criterion for process selection.

- Process resolution: this is also an important aspect that guarantees the accuracy of the AM process [14, 112] and the development of appropriate scaling solutions for nano-, micro- and macro-features [38, 64, 113-116]. Some studies focus on slicing techniques to increase accuracy such as adaptive slicing proposed by Siraskar et al. [117] using volume decomposition by octants.

- Feed material properties: rheological and phase change properties of the feed materials are essential to the success of AM building capabilities especially for achieving standards in material selection [118]. This is a continuous research direction aiming at increasing the spectrum of printable materials and optimising the intrinsic material properties for a better performance during fabrication step [14, 19, 119-121].

- Support material: optimisation of the support material is now fully integrated in numerous commercial solutions, which require supporting of the part during processing. This optimisation relies on different options such as the 


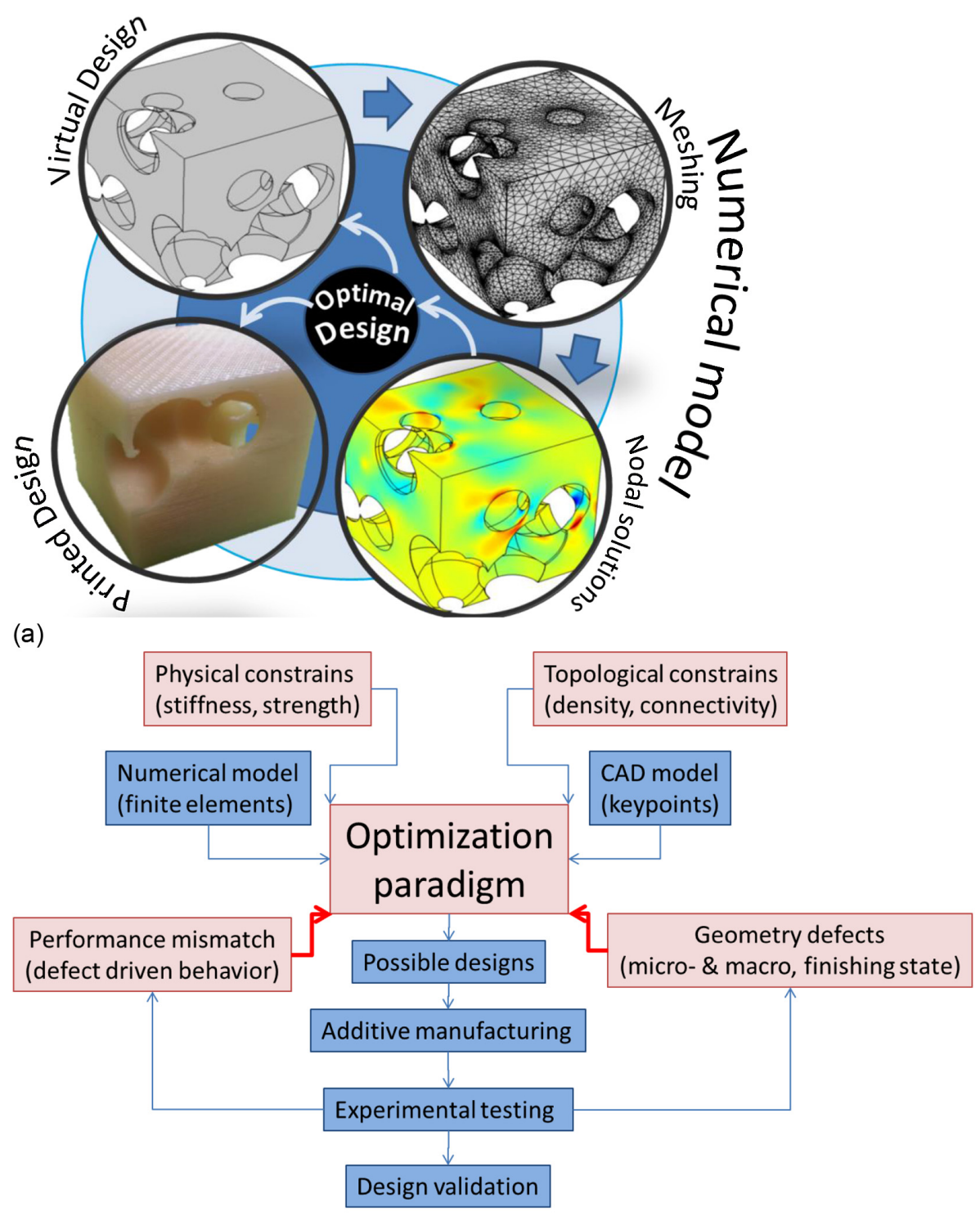

(b)

Figure 5. (a) Classical view of topological optimisation, (b) Modified scheme with defect sensitive topology optimisation of AM.

smart deposition for which only reduced amount of support material is needed [76]. Some research works still contribute in this particular area to improve the spatial distribution of airy support material $[75,122]$.

The logic behind topology optimisation is illustrated in Figure 5. The geometry of the CAD model can be something to discover through the optimisation procedure or assisted by imaging tools such as micro-CT scanning [123]. Since the optimisation combines physical and geometrical constrains, numerical solutions need to be available to predict what would be the result of the part performance $[14,112]$. This is generally addressed using finite element computation [53]. The numerical model needs to converge in all design situations within a short time because the process is meant to be repeated several times. Depending on the nature of the physical constrain, the numerical model can be more or less sophisticated.
For instance, residual stress analysis requires most of the time solving a multi-physics problems [124, 125]. If numerical models are able to handle technological, physical, and geometrical constrains, design guidelines can be adopted by coupling the optimisation tool to decision making paradigms. Some studies show that AM process simulation is possible $[125,126]$ but the ultimate goal would be to bridge such realistic tools with the optimisation paradigm. Recent works prove unfortunately that we are far from such ideal situation [127].

Topology optimisation needs to cope with the specificities of AM. As this process generates a complex network of 3D defects, numerical models need to integrate the result of defect in the analysis as an implicit performance perturbation or explicit defect influence. This is the main difference between the two schemes presented in Figure 5. The classical scheme (Figure 5a) does not handle the defects induced by processing, 


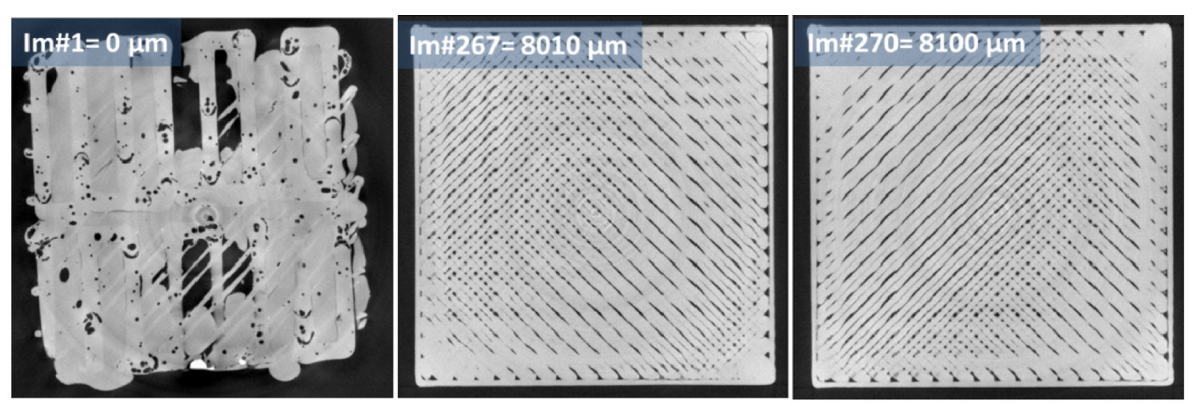

(a)

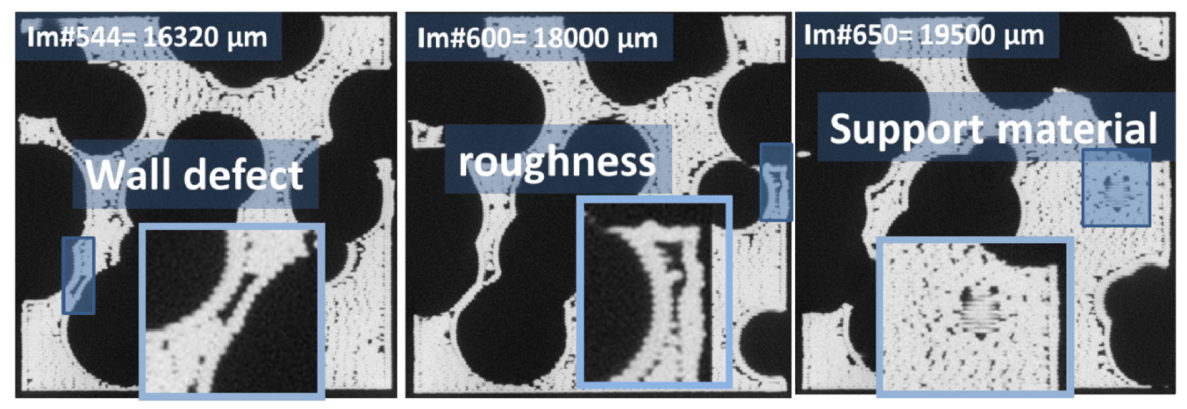

(b)

Figure 6. Microstructural defects in ABS polymer printed using FDM. Analysis is performed using X-ray micro-tomography. Two examples are shown one is (a) a dense ABS block and the other is (b) airy ABS materials exhibiting more than $60 \%$ of porosity.

which makes any deviation from the optimal virtual design a cause of failure. Numerical sizing in aerospace applications [128] is a typical example where such defects can be an issue to validate the final design in airframe development. In the second scheme (Figure 5b), the corrections introduced by the monitoring of the defects helps in guiding the optimisation tool towards the best realistic solution. This resolution is directly related to the AM tooling constrains, for instance the choice of the tip size. If the second scheme is used to consider appropriate selection for tooling options (like nozzle diameter), then such process parameter can be considered as a discrete variable. Optimal design can be searched in a larger space depending on the possibilities offered to select a certain number of available nozzles. Real-time control of AM like the optical tomography [129, 130], thermographic analysis [131] or ultrasonic monitoring $[132,133]$ helps in gaining valuable information about the structural defects that develop during AM processing and their direct consequence on failure of the designed part [73]. This is still a challenging issue as it appears that adequate non-destructive techniques are not yet fully available to evaluate properly AM part performance [52]. This situation can be improved through the development of standards which is still an ongoing process for the validation of testing techniques applicable to AM [134]. One of the most promising techniques to analyse microstructural defects in AM parts is X-ray micro-tomography [135]. This technique is able to provide precise information about the porous network induced by processing, surface roughness, part volume, amount of support material and any other microstructural defect [27]. As the technique relies on transformation of $2 \mathrm{D}$ projections into $3 \mathrm{D}$ image $[136,137]$, structural anisotropy effects can be quantified.
Figure 6 shows two examples of defects revealed in ABS polymer printed using fused deposition modelling. Cross-section views refer to a dense block of ABS $(30 \times 30 \times 30$ $\mathrm{mm}^{3}$ ) analysed using X-ray micro-tomography. This block is oriented at $0^{\circ}$ in the printing plateau, but we notice clearly the crossing of filaments at an angle of $45^{\circ}$ and the presence of bounding layer. In Figure $6 \mathrm{a}$, the resolution of the image is $1077 \times 1062 \times 1059$ voxels, where a voxel is a graphical unit in 3D. The physical size of the voxel determines the accuracy of the structural defect evaluation. In Figure 5a, the voxel size is $30 \mu \mathrm{m}$. More information about the operating conditions can be found in reference [27]. Figure 5a shows the lack of cohesion between successive filaments and tendency to flattening because the filament diameter is tripled during the laying down of the fused matter. The subsequent porosity forms as a regular network of micro-sized defects, and appears to be highly connected. Also, residual support material can be found at the borders, which reveals difficulties of support material removal. The automatic cleaning process is generally followed by manual removal step to ensure that no residual support material is left behind. The second example highlighted in Figure $6 \mathrm{~b}$ shows other imperfections that infiltrate the design of a two phase material. These imperfections are related to discontinuities of matter in the cell walls, the change of geometry due to design mismatch effects and the presence of support material trapped in closed pores of small size.

In several contributions, the red links in Figure $5 \mathrm{~b}$ are ignored as if the approximate result of the optimisation is unavoidably accepted. More recent contributions tackle such links by suggesting corrections of the design based on manufacturability considerations [64]. This is performed, however, 

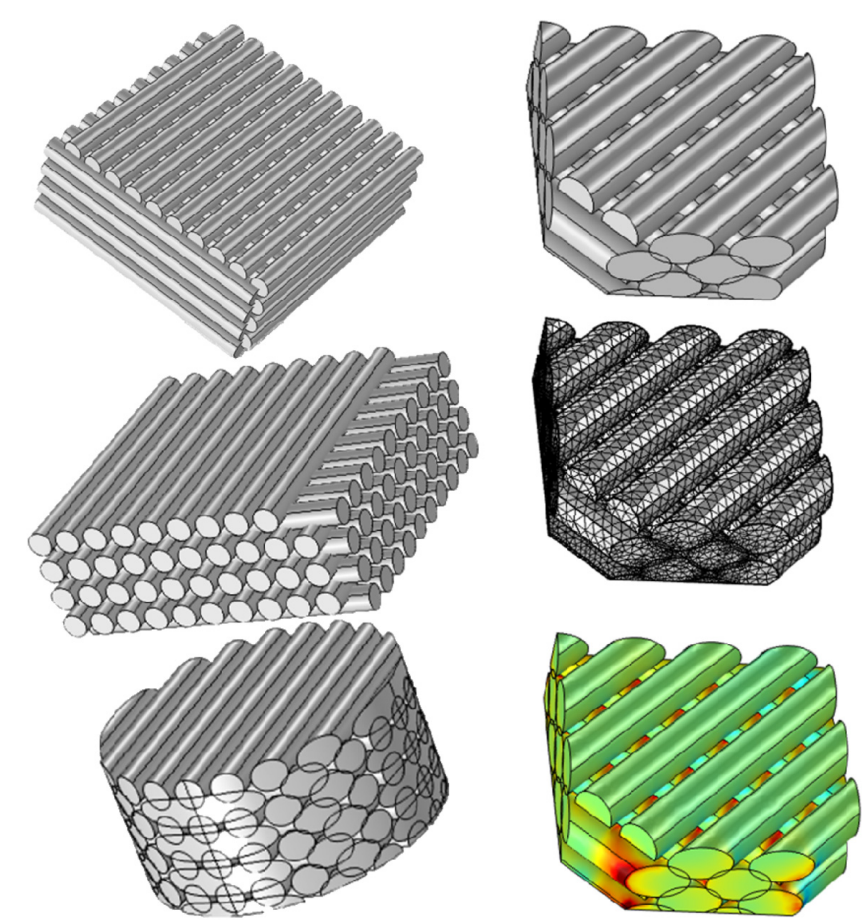

Figure 7. Towards modelling of AM process.

independently from the optimisation tool itself and does not involve defects induced by processing.

\section{Challenges for AM topology optimisation}

One of the important issues that topology optimisation needs to address is the pertinence of the constitutive laws representing the behaviour of the printed materials. Unfortunately, material law implementation is not yet fully revisited leaving an open area for research in this direction [138]. A typical research direction would be to explore interfacial effect in terms of limited load transfer and damage kinetics at the light of results achieved for composite materials [139, 140]. This direction is fully justified by the fact that lack of performance is more associated to the weak adhesion between filaments. Thus, failure mechanisms are likely to be affected by the arrangement of such weak regions [27].

Another concern is the embedding of the microstructural details in the topology optimisation. During the past decades, this opportunity to tune microstructurally the design was out of reach because of computation resource limitations. Now, this is accessible at the cost of using efficient paradigms that avoid unrealistic configurations and constrain the search volume to design-effective solutions. Recent experimental achievements show the potential of AM to tune locally the performance of multi-material parts [39]. The next realistic step would be to promote this kind of experimental attempts to fully automated procedures. The role of microstructural details can be even determinant in hierarchical structures. Indeed, previous studies show large possibilities of airy arrangement using hybrid optimisation strategies [141]. One can imagine the large possibilities of pore connectivity tailoring driven by AM if micro-porosity is considered.
Topology optimisation is not yet ready to provide systematic process error detection for AM. We know that AM processes are exposed to inaccuracy in terms of geometry imperfections, volume mismatch, and undesirable surface texture. All these drawbacks can be properly addressed by a tool that apprehends the limits of the AM processing. Realistic designs with acceptable defects are better than ideal designs with unmeasurable bias. Figure 7 shows some clues about how topology optimisation can achieve a higher sensitivity to defects in AM. A better understanding of the AM defects is a matter of scaling down the numerical model to the size of heterogeneities that are the birth sites of the process-induced defects. Explicit implementation of discontinuities can be handled as well as lack of bonding between layers or filaments. Also more elaborated constitutive laws can be considered in order to take into account anisotropies that are subsequent to the rapid cooling and stretching of the matter.

A straight-A learning paradigm is not also accessible for topology optimisation. The near future developments will meet substantial use of in-situ or in-line monitoring procedures for AM [16, 142]. Topology optimisation can integrate some of these procedures to learn from the design. This requires the combination with another class of algorithms that are derived from artificial intelligence [143]. As an end, the optimal design can be performed using optimal process parameters, which saves a considerable amount of time.

A bigger tool for higher perspectives is what process managers expect from optimisation tools. Topology optimisation can be part of it if other considerations are handled carefully like cost effectiveness with a large material catalogue, material saving logics, automated process selection, scenarios of durability, recyclability and projections of life time. Fully automated decision making processes can be then launched starting from the idea of design to the post-mortem step of the AM part.

Acknowledgements. The authors would like to thank Omar Ben Hassana, Pierre Malige and Julien Grison, from IUT of Nantes, and Kaike Yang from ESAC lab, NPU for their technical assistance on the $3 \mathrm{D}$ printing process and mechanical testing. The authors gratefully acknowledge the International Campus on Safety and Intermodality in Transportation (CISIT), the Nord-Pas-de-Calais Region and the European Community (FEDER funds) for partly funding the $\mathrm{X}$-ray tomography equipment. The authors are thankful to IBSM federation for the financial support and to the Nord-Pas-de-Calais Region (France) for funding Hedi Nouri's post-doctoral grant (contract No 14002212). The second author, ZHANG Weihong, thanks the support by National Natural Science Foundation of China (11432011).

\section{References}

1. Yan X, Gu P. 1996. A review of rapid prototyping technologies and systems. Computer-Aided Design, 28(4), 307-318.

2. Pham DT, Gault RS. 1998. A comparison of rapid prototyping technologies. International Journal of Machine Tools \& Manufacture, 38(10-11), 1257-1287.

3. Yang S, Zhao YF. 2015. Additive manufacturing-enabled design theory and methodology: a critical review. International Journal of Advanced Manufacturing Technology, $80(1-4), 327-342$. 
4. Chiu WK, Yu KM. 2008. Direct digital manufacturing of three-dimensional functionally graded material objects. Computer-Aided Design, 40(12), 1080-1093.

5. Shim JH, Kim AJ, Park JY, Yi N, Kang I, Park J, Rhie JW, Cho DW. 2013. Effect of solid freeform fabrication-based polycaprolactone/poly(lactic-co-glycolic acid)/collagen scaffolds on cellular activities of human adipose-derived stem cells and rat primary hepatocytes. Journal of Materials ScienceMaterials in Medicine, 24(4), 1053-1065.

6. Huang SH, Liu P, Mokasdar A, Hou L. 2013. Additive manufacturing and its societal impact: a literature review. International Journal of Advanced Manufacturing Technology, 67(5-8), 1191-1203.

7. Zhai YW, Lados DA, Lagoy JL. 2014. Additive manufacturing: making imagination the major limitation. JOM, 66(5), 808-816.

8. Schelly C, Anzalone G, Wijnen B, Pearce JM. 2015. Opensource 3-D printing technologies for education: bringing additive manufacturing to the classroom. Journal of Visual Languages and Computing, 28, 226-237.

9. Gress DR, Kalafsky RV. 2015. Geographies of production in 3D: theoretical and research implications stemming from additive manufacturing. Geoforum, 60, 43-52.

10. Kietzmann J, Pitt L, Berthon P. 2015. Disruptions, decisions, and destinations: enter the age of 3-D printing and additive manufacturing. Business Horizons, 58(2), 209-215.

11. Shirazi SFS, Gharehkhani S, Mehrali M, Yarmand H, Metselaar HSC, Kadri NA, Abu Osman NA. 2015. A review on powderbased additive manufacturing for tissue engineering: selective laser sintering and inkjet 3D printing. Science and Technology of Advanced Materials, 16(3), 033502-1-033502-20.

12. Turner BN, Gold SA. 2015. A review of melt extrusion additive manufacturing processes: II. Materials, dimensional accuracy, and surface roughness. Rapid Prototyping Journal, 21(3), 250-261.

13. Gong XB, Anderson T, Chou K. 2012. Review on powderbased electron beam additive manufacturing technology. Proceedings of the ASME/ISCIE International Symposium on Flexible Automation, Isfa 2012, St. Louis, Missouri, USA, 507-515.

14. Huang Y, Leu MC, Mazumder J, Donmez A. 2015. Additive manufacturing: current state, future potential, gaps and needs, and recommendations. Journal of Manufacturing Science and Engineering-Transactions of the ASME, 137(1), 014001-1014001-10.

15. Frazier WE. 2014. Metal additive manufacturing: a review. Journal of Materials Engineering and Performance, 23(6), 1917-1928.

16. Tapia G, Elwany A. 2014. A review on process monitoring and control in metal-based additive manufacturing. Journal of Manufacturing Science and Engineering-Transactions of the ASME, 136(6), 060801-1-060801-10.

17. Vayre B, Vignat F, Villeneuve F. 2012. Metallic additive manufacturing: state-of-the-art review and prospects. Mechanics \& Industry, 13(2), 89-96.

18. Nie B, Yang LM, Huang H, Bai S, Wan P, Liu J. 2015. Femtosecond laser additive manufacturing of iron and tungsten parts. Applied Physics A-Materials Science \& Processing, 119(3), 1075-1080.

19. Finke S, Feenstra FK. 2002. Solid freeform fabrication by extrusion and deposition of semi-solid alloys. Journal of Materials Science, 37(15), 3101-3106.
20. Milewski JO, Dickerson PG, Nemec RB, Lewis GK, Fonseca JC. 1999. Application of a manufacturing model for the optimization of additive processing of Inconel alloy 690 . Journal of Materials Processing Technology, 91(1-3), 18-28.

21. Xu W, Brandt M, Sun S, Elambasseril J, Liu Q, Latham K, Xia K, Qian M. 2015. Additive manufacturing of strong and ductile Ti-6Al-4V by selective laser melting via in situ martensite decomposition. Acta Materialia, 85, 74-84.

22. Tang HP, Yang GY, Jia WP, He WW, Lu SL, Qian M. 2015. Additive manufacturing of a high niobium-containing titanium aluminide alloy by selective electron beam melting. Materials Science and Engineering A-Structural Materials Properties Microstructure and Processing, 636, 103-107.

23. Deckers J, Vleugels J, Kruthl JP. 2014. Additive manufacturing of ceramics: a review. Journal of Ceramic Science and Technology, 5(4), 245-260.

24. Chappell WJ, Reilly C, Halloran J, Katehi LPB. 2003. Ceramic synthetic substrates using solid freeform fabrication. IEEE Transactions on Microwave Theory and Techniques, 51(3), 752-760.

25. Tang HH, Yen HC. 2015. Slurry-based additive manufacturing of ceramic parts by selective laser burn-out. Journal of the European Ceramic Society, 35(3), 981-987.

26. Gaytan SM, Cadena MA, Karim H, Delfin D, Lin Y, Espalin D, MacDonald E, Wicker RB. 2015. Fabrication of barium titanate by binder jetting additive manufacturing technology. Ceramics International, 41(5), 6610-6619.

27. Guessasma S, Belhabib S, Nouri H. 2015. Significance of pore percolation to drive anisotropic effects of $3 \mathrm{D}$ printed polymers revealed with $\mathrm{X}$-ray $\mu$-tomography and finite element computation. Polymer, 81, 29-36.

28. Shaffer S, Yang KJ, Vargas J, Di Prima MA, Voit W. 2014. On reducing anisotropy in $3 \mathrm{D}$ printed polymers via ionizing radiation. Polymer, 55(23), 5969-5979.

29. Hatzenbichler M, Geppert M, Seemann R, Stampfl J. 2013. Additive manufacturing of photopolymers using the texas instruments DLP lightcrafter. Emerging Digital Micromirror Device Based Systems and Applications V, 8618, 86180A-186180A-8.

30. Puppi D, Mota C, Gazzarri M, Dinucci D, Gloria A, Myrzabekova M, Ambrosio L, Chiellini F. 2012. Additive manufacturing of wet-spun polymeric scaffolds for bone tissue engineering. Biomedical Microdevices, 14(6), 1115-1127.

31. Quan Z, Wu A, Keefe M, Qin X, Yu J, Suhr J, Byun J-H, Kim B-S, Chou T-W. 2015. Additive manufacturing of multidirectional preforms for composites: opportunities and challenges. Materials Today, 18, 503-512.

32. Ning FD, Cong WL, Qiu JJ, Wei JH, Wang SR. 2015. Additive manufacturing of carbon fiber reinforced thermoplastic composites using fused deposition modeling. Composites Part BEngineering, 80, 369-378.

33. Gu DD, Chang F, Dai DH. 2015. Selective laser melting additive manufacturing of novel aluminum based composites with multiple reinforcing phases. Journal of Manufacturing Science and Engineering-Transactions of the ASME, 137(2).

34. Tekinalp HL, Kunc V, Velez-Garcia GM, Duty CE, Love LJ, Naskar AK, Blue CA, Ozcan S. 2014. Highly oriented carbon fiber-polymer composites via additive manufacturing. Composites Science and Technology, 105, 144-150.

35. Lee JS, Cha HD, Shim JH, Jung JW, Kim JY, Cho DW. 2012. Effect of pore architecture and stacking direction on mechanical properties of solid freeform fabrication-based scaffold for 
bone tissue engineering. Journal of Biomedical Materials Research Part A, 100A(7), 1846-1853.

36. Sa AME, Mello VM, Echavarria KR, Covill D. 2015. Adaptive voids primal and dual adaptive cellular structures for additive manufacturing. Visual Computer, 31(6-8), 799-808.

37. Takezawa A, Kobashi M, Kitamura M. 2015. Porous composite with negative thermal expansion obtained by photopolymer additive manufacturing. APL Materials, 3(7), 076103-1-076103-6.

38. Watjen AM, Gingter P, Kramer M, Telle R. 2014. Novel prospects and possibilities in additive manufacturing of ceramics by means of direct inkjet printing. Advances in Mechanical Engineering, 2014, 141346.

39. Sugavaneswaran M, Arumaikkannu G. 2014. Modelling for randomly oriented multi material additive manufacturing component and its fabrication. Materials \& Design, 54, 779-785.

40. Herderick ED. 2015. Progress in additive manufacturing. JOM, 67(3), 580-581.

41. Giannatsis J, Dedoussis V. 2009. Additive fabrication technologies applied to medicine and health care: a review. International Journal of Advanced Manufacturing Technology, 40(1-2), 116-127.

42. Vaezi M, Seitz H, Yang SF. 2013. A review on 3D microadditive manufacturing technologies. International Journal of Advanced Manufacturing Technology, 67(5-8), 1721-1754.

43. Venekamp NJR, Le Fever HT. 2015. Application areas of additive manufacturing from curiosity to application. IEEE Technology and Society Magazine, 34(3), 81-87.

44. Lipton JI, Cutler M, Nigi F, Cohen D, Lipson H. 2015. Additive manufacturing for the food industry. Trends in Food Science \& Technology, 43(1), 114-123.

45. Heinrich A, Maillard P, Suckow A, Grzesiak A, Sorg P, Berger U. 2015. Additive manufacturing - a new approach for individualized optical shape metrology. Optical Measurement Systems for Industrial Inspection Ix, 9525, 95251T-195251T-10.

46. Dickson MN. 2015. Soft strain sensors fabricated through additive manufacturing. MRS Bulletin, 40(6), 463.

47. Setaki F, Tenpierik M, Turrin M, van Timmeren A. 2014. Acoustic absorbers by additive manufacturing. Building and Environment, 72, 188-200.

48. Ho CMB, Ng SH, Yoon YJ. 2015. A review on 3D printed bioimplants. International Journal of Precision Engineering and Manufacturing, 16(5), 1035-1046.

49. Butscher A, Bohner M, Hofmann S, Gauckler L, Muller R. 2011. Structural and material approaches to bone tissue engineering in powder-based three-dimensional printing. Acta Biomaterialia, 7(3), 907-920.

50. Cox SC, Thornby JA, Gibbons GJ, Williams MA, Mallick KK. 2015. 3D printing of porous hydroxyapatite scaffolds intended for use in bone tissue engineering applications. Materials Science \& Engineering C-Materials for Biological Applications, 47, 237-247.

51. Jiang CP, Chen YY, Hsieh MF, Lee HM. 2013. Solid freeform fabrication and in-vitro response of osteoblast cells of mPEGPCL-mPEG bone scaffolds. Biomedical Microdevices, 15(2), 369-379.

52. Waller JM, Saulsberry RL, Parker BH, Hodges KL, Burke ER, Taminger KM. 2015. Summary of NDE of Additive Manufacturing Efforts in NASA. 41st Annual Review of Progress in Quantitative Nondestructive Evaluation, Vol. 34, 1650, 51-62.
53. Zhu WJ, Zhao XL, Zhang W, Ren K, Zhang ZY, Li DC. 2014. Design and evaluation of fully configured models built by additive manufacturing. AIAA Journal, 52(7), 1441-1451.

54. Zhu J-H, Zhang W-H, Xia L. 2015. Topology optimization in aircraft and aerospace structures design. Archives of Computational Methods in Engineering, 1-28.

55. Gu XJ, Zhu JH, Zhang WH. 2012. The lattice structure configuration design for stereolithography investment casting pattern using topology optimization. Rapid Prototyping Journal, 18(5), 353-361.

56. Engstrom DS, Porter B, Pacios M, Bhaskaran H. 2014. Additive nanomanufacturing - a review. Journal of Materials Research, 29(17), 1792-1816.

57. Chakraborty D, Reddy BA, Choudhury AR. 2008. Extruder path generation for curved layer fused deposition modeling. Computer-Aided Design, 40(2), 235-243.

58. Lee CS, Kim SG, Kim HJ, Ahn SH. 2007. Measurement of anisotropic compressive strength of rapid prototyping parts. Journal of Materials Processing Technology, 187, 627-630.

59. Ahn SH, Montero M, Odell D, Roundy S, Wright PK. 2002. Anisotropic material properties of fused deposition modeling ABS. Rapid Prototyping Journal, 8(4), 248-257.

60. Lee PH, Chung H, Lee SW, Yoo J, Ko J. 2014. Review: dimensional accuracy in additive manufacturing processes. Proceedings of the ASME 9th International Manufacturing Science and Engineering Conference, 2014, Detroit, Michigan, USA, vol. 1, V001T04A045.

61. Zhu YY, Tian XJ, Li J, Wang HM. 2015. The anisotropy of laser melting deposition additive manufacturing Ti-6.5Al3.5Mo-1.5Zr-0.3Si titanium alloy. Materials \& Design, 67, $538-542$.

62. Rosa B, Mognol P, Hascoet JY. 2015. Laser polishing of additive laser manufacturing surfaces. Journal of Laser Applications, 27, S29102-1-S29102-7.

63. Pinto JM, Arrieta C, Andia ME, Uribe S, Ramos-Grez J, Vargas A, Irarrazaval P, Tejos C. 2015. Sensitivity analysis of geometric errors in additive manufacturing medical models. Medical Engineering \& Physics, 37(3), 328-334.

64. Nelaturi S, Kim W, Kurtoglu T. 2015. Manufacturability feedback and model correction for additive manufacturing. Journal of Manufacturing Science and Engineering-Transactions of the ASME, 137(2), 021015-1-021015-9.

65. Wang T, Zhu YY, Zhang SQ, Tang HB, Wang HM. 2015. Grain morphology evolution behavior of titanium alloy components during laser melting deposition additive manufacturing. Journal of Alloys and Compounds, 632, 505-513.

66. Ma Y, Cuiuri D, Hoye N, Li HJ, Pan ZX. 2015. The effect of location on the microstructure and mechanical properties of titanium aluminides produced by additive layer manufacturing using in-situ alloying and gas tungsten arc welding. Materials Science and Engineering A-Structural Materials Properties Microstructure and Processing, 631, 230-240.

67. Hong C, Gu DD, Dai DH, Alkhayat M, Urban W, Yuan PP, Cao S, Gasser A, Weisheit A, Kelbassa I, Zhong ML, Poprawe R. 2015. Laser additive manufacturing of ultrafine TiC particle reinforced Inconel 625 based composite parts: tailored microstructures and enhanced performance. Materials Science and Engineering A-Structural Materials Properties Microstructure and Processing, 635, 118-128.

68. Carroll BE, Palmer TA, Beese AM. 2015. Anisotropic tensile behavior of Ti-6Al-4V components fabricated with directed 
energy deposition additive manufacturing. Acta Materialia, 87, 309-320.

69. Thrimurthulu K, Pandey PM, Reddy NV. 2004. Optimum part deposition orientation in fused deposition modeling. International Journal of Machine Tools \& Manufacture, 44(6), 585-594.

70. Rua Y, Muren R, Reckinger S. 2015. Limitations of additive manufacturing on microfluidic heat exchanger components. Journal of Manufacturing Science and Engineering-Transactions of the ASME, 137(3), 034504-1-034504-5.

71. Carneiro OS, Silva AF, Gomes R. 2015. Fused deposition modeling with polypropylene. Materials \& Design, 83, 768-776.

72. Scudino S, Unterdorfer C, Prashanth KG, Attar H, Ellendt N, Uhlenwinkel V, Eckert J. 2015. Additive manufacturing of Cu10Sn bronze. Materials Letters, 156, 202-204.

73. Foster BK, Reutzel EW, Nassar AR, Dickman CJ, Hall BT. 2015. A brief survey of sensing for metal-based powder bed fusion additive manufacturing. Dimensional Optical Metrology and Inspection for Practical Applications Iv, 9489, 94890B-1-94890B-9.

74. Furumoto T, Koizumi A, Alkahari MR, Anayama R, Hosokawa A, Tanaka R, Ueda T. 2015. Permeability and strength of a porous metal structure fabricated by additive manufacturing. Journal of Materials Processing Technology, 219, 10-16.

75. $\mathrm{Hu} \mathrm{KL}$, Jin S, Wang CCL. 2015. Support slimming for single material based additive manufacturing. Computer-Aided Design, 65, 1-10.

76. Jin YA, He Y, Fu JZ. 2015. Support generation for additive manufacturing based on sliced data. International Journal of Advanced Manufacturing Technology, 80(9-12), 2041-2052.

77. Mohamed OA, Masood SH, Bhowmik JL. 2015. Optimization of fused deposition modeling process parameters: a review of current research and future prospects. Advances in Manufacturing, 3(1), 42-53.

78. Zhou C, Chen Y, Waltz RA. 2009. Optimized mask image projection for solid freeform fabrication. Journal of Manufacturing Science and Engineering-Transactions of the ASME, 131(6), 061004-1-061004-12.

79. Garg A, Lam JSL, Savalani MM. 2015. A new computational intelligence approach in formulation of functional relationship of open porosity of the additive manufacturing process. International Journal of Advanced Manufacturing Technology, 80(1-4), 555-565.

80. Mun J, Yun BG, Ju J, Chang B. 2015. Indirect additive manufacturing based casting of a periodic $3 \mathrm{D}$ cellular metal flow simulation of molten aluminum alloy. Journal of Manufacturing Processes, 17, 28-40.

81. Giannitelli SM, Mozetic P, Trombetta M, Rainer A. 2015. Combined additive manufacturing approaches in tissue engineering. Acta Biomaterialia, 24, 1-11.

82. Rogers CM, Morris GE, Gould TWA, Bail R, Toumpaniari S, Harrington H, Dixon JE, Shakesheff KM, Segal J, Rose FRAJ. 2014. A novel technique for the production of electrospun scaffolds with tailored three-dimensional micro-patterns employing additive manufacturing. Biofabrication, 6(3), 035003.

83. Newman ST, Zhu ZC, Dhokia V, Shokrani A. 2015. Process planning for additive and subtractive manufacturing technologies. CIRP Annals-Manufacturing Technology, 64(1), 467-470.

84. Jin GQ, Li WD. 2013. Adaptive rapid prototyping/manufacturing for functionally graded material-based biomedical models. International Journal of Advanced Manufacturing Technology, 65(1-4), 97-113.
85. Zhou MY, Xi JT, Yan JQ. 2004. Modeling and processing of functionally graded materials for rapid prototyping. Journal of Materials Processing Technology, 146(3), 396-402.

86. Roper DA, Good BL, McCauley R, Yarlagadda S, Smith J, Good A, Pa P, Mirotznik MS. 2014. Additive manufacturing of graded dielectrics. Smart Materials and Structures, 23(4), 045029.

87. Becker R, Grzesiak A, Henning A. 2005. Rethink assembly design. Assembly Automation, 25(4), 262-266.

88. Zhang P, Toman J, Yu Y, Biyikli E, Kirca M, Chmielus M, To AC. 2015. Efficient design-optimization of variable-density hexagonal cellular structure by additive manufacturing: theory and validation. Journal of Manufacturing Science and Engineering-Transactions of the ASME, 137(2), 021004-1021004-8.

89. Yang L, Harrysson O, West H, Cormier D. 2015. Mechanical properties of 3D re-entrant honeycomb auxetic structures realized via additive manufacturing. International Journal of Solids and Structures, 69-70, 475-490.

90. Chen JN, Ahmad R, Suenaga H, Li W, Sasaki K, Swain M, Li Q. 2015. Shape optimization for additive manufacturing of removable partial dentures - a new paradigm for prosthetic CAD/CAM. PLos One, 10(7), 0132552.

91. Denlinger ER, Heigel JC, Michaleris P, Palmer TA. 2015. Effect of inter-layer dwell time on distortion and residual stress in additive manufacturing of titanium and nickel alloys. Journal of Materials Processing Technology, 215, 123-131.

92. Thompson B, Yoon HS. 2014. Efficient path planning algorithm for additive manufacturing systems. IEEE Transactions on Components Packaging and Manufacturing Technology, 4(9), 1555-1563.

93. Kim HC, Choi KH, Doh YH, Kim DS. 2009. Fabrication of parts and their evaluation using a dual laser in the solid freeform fabrication system. Journal of Materials Processing Technology, 209(10), 4857-4866.

94. Ding DH, Pan ZX, Cuiuri D, Li HJ. 2015. Wire-feed additive manufacturing of metal components: technologies, developments and future interests. International Journal of Advanced Manufacturing Technology, 81(1-4), 465-481.

95. Ren L, Sparks T, Ruan JZ, Liou F. 2008. Process planning strategies for solid freeform fabrication of metal parts. Journal of Manufacturing Systems, 27(4), 158-165.

96. Paul R, Anand S. 2015. A new Steiner patch based file format for additive manufacturing processes. Computer-Aided Design, 63, 86-100.

97. Xu AP, Shaw LL. 2005. Equal distance offset approach to representing and process planning for solid freeform fabrication of functionally graded materials. Computer-Aided Design, 37(12), 1308-1318.

98. Ding DH, Pan ZX, Cuiuri D, Li HJ. 2015. A multi-bead overlapping model for robotic wire and arc additive manufacturing (WAAM). Robotics and Computer-Integrated Manufacturing, 31, 101-110.

99. Song X, Pan YY, Chen Y. 2015. Development of a low-cost parallel kinematic machine for multidirectional additive manufacturing. Journal of Manufacturing Science and Engineering-Transactions of the ASME, 137(2), 021005-1021005-13.

100. Arntz K, Wegener M, Liu Y. 2015. Computer aided manufacturing supported process planning of additive manufacturing by laser deposition welding. Journal of Laser Applications, 27, S14002-1-S14002-5. 
101. Seifert T, Sowade E, Roscher F, Wiemer M, Gessner T, Baumann RR. 2015. Additive manufacturing technologies compared: morphology of deposits of silver ink using inkjet and aerosol jet printing. Industrial \& Engineering Chemistry Research, 54(2), 769-779.

102. Palanivel S, Nelaturu P, Glass B, Mishra RS. 2015. Friction stir additive manufacturing for high structural performance through microstructural control in an Mg based WE43 alloy. Materials \& Design, 65, 934-952.

103. Monaghan T, Capel AJ, Christie SD, Harris RA, Friel RJ. 2015. Solid-state additive manufacturing for metallized optical fiber integration. Composites Part A-Applied Science and Manufacturing, 76, 181-193.

104. Sundaram MM, Kamaraj AB, Kumar VS. 2015. Mask-less electrochemical additive manufacturing: a feasibility study. Journal of Manufacturing Science and Engineering-Transactions of the ASME, 137(2), 021006-1-021006-9.

105. Wang H, Jiang W, Valant M, Kovacevic R. 2003. Microplasma powder deposition as a new solid freeform fabrication process. Proceedings of the Institution of Mechanical Engineers Part B-Journal of Engineering Manufacture, 217(12), 1641-1650.

106. Leong KF, Cheah CM, Chua CK. 2003. Solid freeform fabrication of three-dimensional scaffolds for engineering replacement tissues and organs. Biomaterials, 24(13), 2363-2378.

107. Cai K, Guo D, Huang Y, Yang JL. 2003. Solid freeform fabrication of alumina ceramic parts through a lost mould method. Journal of the European Ceramic Society, 23(6), 921925.

108. Guo D, Cai K, Nan C, Li LT, Gul ZL. 2002. Gelcasting based solid freeform fabrication of piezoelectric ceramic objects. Scripta Materialia, 47(6), 383-387.

109. Sohn H, Yang DY. 2002. Selective infiltration of superheated micro-sized droplets of a tin-lead alloy into a preheated powder layer for a novel solid freeform fabrication process. Journal of Materials Science Letters, 21(21), 1717-1719.

110. Mancanares CG, Zancul ED, da Silva JC, Miguel PAC. 2015. Additive manufacturing process selection based on parts' selection criteria. International Journal of Advanced Manufacturing Technology, 80(5-8), 1007-1014.

111. Price S, Cheng B, Lydon J, Cooper K, Chou K. 2014. On process temperature in powder-bed electron beam additive manufacturing: process parameter effects. Journal of Manufacturing Science and Engineering-Transactions of the ASME, 136(6), 061019-1-061019-10.

112. Wei C, Dong JY. 2014. Development and modeling of melt electrohydrodynamic-jet printing of phase-change inks for high-resolution additive manufacturing. Journal of Manufacturing Science and Engineering-Transactions of the ASME, 136(6), 061010-1-061010-7.

113. Kang HW, Seol YJ, Cho DW. 2009. Development of an indirect solid freeform fabrication process based on microstereolithography for $3 \mathrm{D}$ porous scaffolds. Journal of Micromechanics and Microengineering, 19(1), 015011.

114. Mondrinos MJ, Dembzynski R, Lu L, Byrapogu VKC, Wootton DM, Lelkes PI, Zhou J. 2006. Porogen-based solid freeform fabrication of polycaprolactone-calcium phosphate scaffolds for tissue engineering. Biomaterials, 27(25), 4399-4408.

115. Choi H, Yang Y, Li XC. 2005. Experimental study on integration of laser-based additive/subtractive processes for meso/micro solid freeform fabrication. International Journal of Advanced Manufacturing Technology, 26(4), 335-341.
116. Yoshida H, Igarashi T, Obuchi Y, Takami Y, Sato J, Araki M, Miki M, Nagata K, Sakai K, Igarashi S. 2015. Architecturescale human-assisted additive manufacturing. ACM Transactions on Graphics, 34(4), 88.

117. Siraskar N, Paul R, Anand S. 2015. Adaptive slicing in additive manufacturing process using a modified boundary octree data structure. Journal of Manufacturing Science and Engineering-Transactions of the ASME, 137(1), 011007-1011007-11.

118. Slotwinski JA, Garboczi EJ, Stutzman PE, Ferraris CF, Watson SS, Peltz MA. 2014. Characterization of metal powders used for additive manufacturing. Journal of Research of the National Institute of Standards and Technology, 119, 460-493.

119. Sakar-Deliormanli A, Celik E, Polat M. 2008. Rheological behavior of PMN gels for solid freeform fabrication. Colloids and Surfaces A-Physicochemical and Engineering Aspects, 324(1-3), 159-166.

120. Yen HC. 2015. Experimental studying on development of slurry-layer casting system for additive manufacturing of ceramics. International Journal of Advanced Manufacturing Technology, 77(5-8), 915-925.

121. Shiva S, Palani IA, Mishra SK, Paul CP, Kukreja LM. 2015. Investigations on the influence of composition in the development of $\mathrm{Ni}$-Ti shape memory alloy using laser based additive manufacturing. Optics and Laser Technology, 69, 44-51.

122. Strano G, Hao L, Everson RM, Evans KE. 2013. A new approach to the design and optimisation of support structures in additive manufacturing. International Journal of Advanced Manufacturing Technology, 66(9-12), 1247-1254.

123. Cooper D, Thornby J, Blundell N, Henrys R, Williams MA, Gibbons G. 2015. Design and manufacture of high performance hollow engine valves by additive layer manufacturing. Materials \& Design, 69, 44-55.

124. Zohdi TI. 2015. Modeling and simulation of cooling-induced residual stresses in heated particulate mixture depositions in additive manufacturing. Computational Mechanics, 56(4), 613-630.

125. Bai XW, Zhang HO, Wang GL. 2015. Modeling of the moving induction heating used as secondary heat source in weld-based additive manufacturing. International Journal of Advanced Manufacturing Technology, 77(1-4), 717-727.

126. Brant AM, Sundaram MM, Kamaraj AB. 2015. Finite element simulation of localized electrochemical deposition for maskless electrochemical additive manufacturing. Journal of Manufacturing Science and Engineering-Transactions of the ASME, 137(1), 011018-1-011018-9.

127. Kranz J, Herzog D, Emmelmann C. 2015. Design guidelines for laser additive manufacturing of lightweight structures in TiAl6V4. Journal of Laser Applications, 27, S14001-1S14001-16.

128. Grihon S, Krog L, Bassir D. 2011. Numerical optimization applied to structure sizing at AIRBUS: a multi-step process. International Journal for Simulation and Multidisciplinary Design Optimization, 3(4), 432-442.

129. Zenzinger G, Bamberg J, Ladewig A, Hess T, Henkel B, Satzger W. 2015. Process monitoring of additive manufacturing by using optical tomography. 41st Annual Review of Progress in Quantitative Nondestructive Evaluation, Vol. 34, 1650, 164-170.

130. Carl V. 2015. Monitoring system for the quality assessment in additive manufacturing. 41st Annual Review of Progress in 
Quantitative Nondestructive Evaluation, Vol. 34, 1650, 171176.

131. Krauss H, Zeugner T, Zaeh MF. 2015. Thermographic process monitoring in powderbed based additive manufacturing. 41st Annual Review of Progress in Quantitative Nondestructive Evaluation, Vol. 34, 1650, 177-183.

132. Rieder H, Dillhofer A, Spies M, Bamberg J, Hess T. 2015. Ultrasonic online monitoring of additive manufacturing processes based on selective laser melting. 41st Annual Review of Progress in Quantitative Nondestructive Evaluation, Vol. 34, 1650, 184-191.

133. Everton S, Dickens P, Tuck C, Dutton B. 2015. Evaluation of laser ultrasonic testing for inspection of metal additive manufacturing. Laser 3d Manufacturing Ii, 9353, 935316-1935316-8.

134. Monzon MD, Ortega Z, Martinez A, Ortega F. 2015. Standardization in additive manufacturing: activities carried out by international organizations and projects. International Journal of Advanced Manufacturing Technology, 76(5-8), 1111-1121.

135. Raguvarun K, Balasubramaniam K, Rajagopal P, Palanisamy S, Nagarajah R, Hoye N, Curiri D, Kapoor A. 2015. A study of internal structure in components made by additive manufacturing process using 3D X-ray tomography. 41st Annual Review of Progress in Quantitative Nondestructive Evaluation, Vol. 34, 1650, 146-155.

136. Guessasma S, Nouri H. 2015. Compression behaviour of bread crumb up to densification investigated using X-ray tomography and finite element computation. Food Research International, 72, 140-148.
137. Ayadi A, Nouri H, Guessasma S, Roger F. 2015. An original approach to assess elastic properties of a short glass fibre reinforced thermoplastic combining X-ray tomography and finite element computation. Composite Structures, 125, 277286.

138. Adamczak S, Bochnia J, Kaczmarska B. 2015. An analysis of tensile test results to assess the innovation risk for an additive manufacturing technology. Metrology and Measurement Systems, 22(1), 127-138.

139. Guessasma S, Bassir DH. 2010. Identification of mechanical properties of biopolymer composites sensitive to interface effect using hybrid approach. Mechanics of Materials, 42(3), 344-353.

140. Hbib M, Guessasma S, Bassir D, Benseddiq N. 2011. Interfacial damage in biopolymer composites reinforced using hemp fibres: finite element simulation and experimental investigation. Composites Science and Technology, 71(11), 1419-1426.

141. Guessasma S, Bassir D. 2010. Optimization of the mechanical properties of virtual porous solids using a hybrid approach. Acta Materialia, 58(2), 716-725.

142. Xiong J, Zhang GJ. 2014. Adaptive control of deposited height in GMAW-based layer additive manufacturing. Journal of Materials Processing Technology, 214(4), 962-968.

143. Witherell P, Feng S, Simpson TW, Saint John DB, Michaleris P, Liu ZK, Chen LQ, Martukanitz R. 2014. Toward metamodels for composable and reusable additive manufacturing process models. Journal of Manufacturing Science and Engineering-Transactions of the ASME, 136(6), 061025-1061025-9.

Cite this article as: Guessasma S, Zhang W, Zhu J, Belhabib S \& Nouri H: Challenges of additive manufacturing technologies from an optimisation perspective. Int. J. Simul. Multisci. Des. Optim., 2015, 6, A9. 